\title{
Unusual Presentation in a Case of Intravascular Papillary Endothelial Hyperplasia
}

\author{
Laura Fernández-Cuevas ${ }^{1}$, Gisela Navarrete-Franco ${ }^{2}$, Flor Patricia Carmona-Contreras ${ }^{3}$, Alba \\ Cicero-Casarrubias ${ }^{4}$, Lilly Esquivel-Pedraza ${ }^{4,5 *}$ \\ ${ }^{1}$ Oral Pathology Clinic, Centro Dermatológico "Dr. Ladislao de la Pascua" \& School of Dentistry, Universidad \\ Intercontinental, Mexico City, Mexico \\ ${ }^{2}$ Pathology Department, Centro Dermatológico "Dr. Ladislao de la Pascua" \\ ${ }^{3}$ Resident. Centro Dermatológico "Dr. Ladislao de la Pascua" \\ ${ }^{4}$ Dermatology Department, Instituto Nacional de Ciencias Médicas y Nutrición "Salvador Zubirán" \\ ${ }^{5}$ Health Care Department, Universidad Autónoma Metropolitana
}

*Corresponding Author

Lilly Esquivel-Pedraza

\section{Article History}

Received: 02.07.2020

Accepted: 09.07.2020

Published: 16.07.2020

\begin{abstract}
Background: Intravascular papillary endothelial hyperplasia, also known as Masson's tumor, is a reactive benign lesion of vascular origin. Only few cases have been reported in the literature and the clinical features may mimic other benign and malignant lesions, making the clinical diagnosis challenging. Main observations: We report an uncommon case with detailed clinical findings affecting the oral cavity. Conclusions: We present an exceptional case of intravascular papillary endothelial hyperplasia. The oral mucosa is commonly affected by vascular lesions so it is worthy to consider intravascular papillary endothelial hyperplasia in the differential diagnosis.
\end{abstract}

Keywords: intravascular papillary endothelial hyperplasia, Masson's tumor, mouth diseases, vascular lesions.

\section{INTRODUCTION}

Intravascular papillary endothelial hyperplasia (IPEH) is a reactive benign lesion of vascular origin that is caused by proliferation of endothelial cells in the vascular lumen of dilated vessels or within preexisting vascular lesions, frequently associated with thrombus [1]. This tumor was first described in 1923 by Pierre Masson. He reported a case in a 68 year-old male and it was termed intravascular vegetating hemangioendothelioma[2]. IPEH is alternatively referred to as Masson's tumor, intravenous atypical vascular proliferation, intravascular angiomatosis, Masson's intravascular hemangioendothelioma and Masson's pseudoangiosarcoma [3]. In 1932, Henschen suggested the reactive nature of the lesion [4] and was termed IPEH in 1976 by Clearkin and Enzinger[5].

The IPEH is a rare tumor that may mimic multiple benign and malignant lesions making the clinical diagnosis challenging, thus its identification usually relies on the histopathological examination. We report an atypical case evaluated at the Pascua Dermatologic Center, a national dermatologic referral center.

\section{CaSe Report}

A previously healthy 27 year-old male was examined at the Oral Pathology Clinic in 2012. He presented with a three-month history of a rapidly growing exophytic nodule affecting left upper vermillion border of the lip and labial mucosa. Examination revealed a $2.0 \times 1.6 \mathrm{~cm}$ nodule that was firm, well circumscribed and sessile; there were no apparent changes in the overlying mucosa. The patient referred pain when eating (Fig. 1); he denied previous trauma. A tumor of minor salivary glands was suspected and an excisional biopsy was performed under local anesthesia.

Copyright @ 2020: This is an open-access article distributed under the terms of the Creative Commons Attribution license which permits unrestricted use, distribution, and reproduction in any medium for non commercial use (NonCommercial, or CC-BY-NC) provided the original author and source are credited. 
Histopathological analysis showed a well-circumscribed lesion surrounded by a fibrous capsule. There was formation of papillary structures lined by a single layer of endothelial cells in the vascular lumen; thrombi were observed within the vascular lumen, and a moderate inflammatory infiltrate was observed (Fig. 2 A \& B). No recurrence of tumor has been noted after a three-year follow-up period.

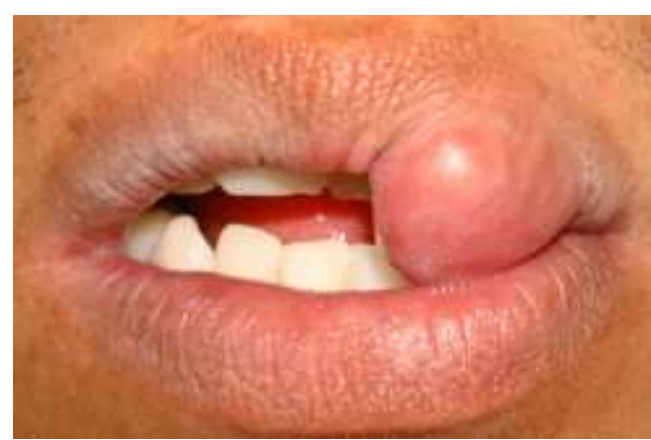

Fig-1: Firm and painful exophytic nodule affecting left upper vermillion, note it prevents adequate mouth closure

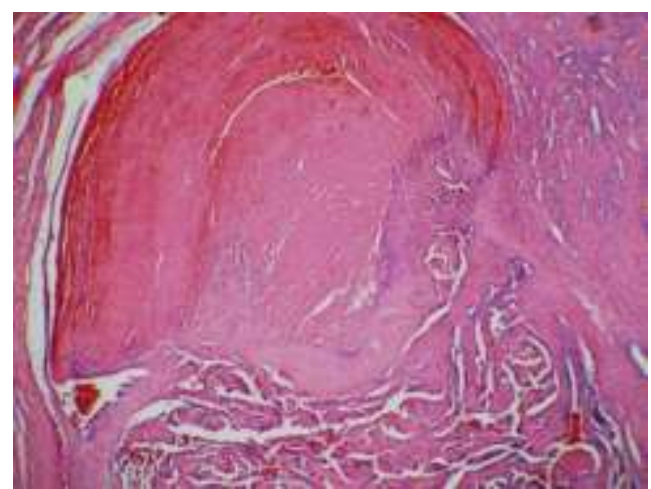

Fig-2A: Panoramic view of the lesion showing the organizing thrombus occupying a dilated vessel. (Hematoxylin and eosin, 40x)

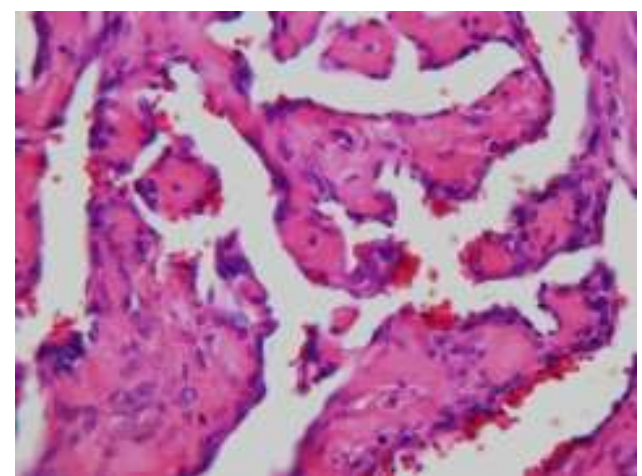

Fig-2B: High power view showing formation of papillary structures lined by a single layer of hyperchromatic endothelial cells. (Hematoxylin and eosin, $400 x)$

\section{DISCUSSION}

The IPEH is an uncommon tumor, frequently linked to trauma [6, 7]. Most cases are located in the head and neck [8] usually affecting the oral cavity [6]; being vermillion border the site most frequently involved [9], similar to our case.

Clinical features in IPEH are nonspecific, but its vascular nature is frequently evident, therefore the differential diagnosis usually includes vascular tumors. Clinically, it appears as a firm or soft nodule with slight elevation, overlying skin may be red or erythematoviolaceous. It is characterized by a slow growth and it is commonly asymptomatic. The lesions usually measure less than two $\mathrm{cm}$ [9].

It stands out that our case lacked a vascular appearance and a previous history of trauma; it presented as a painful rapid evolving nodule with a firm consistency, the latter is not the usual presentation in mouth; for the previous reasons IPEH was not suspected. IPEH is a histopathological diagnosis, in fact it has not been suspected in any of the previously reported cases. On the other hand, many vascular lesions commonly found in the oral mucosa are clinically 
diagnosed as venous lakes and they are not excised or the histologic specimen is not analyzed, so in this location IPEH may be underrecognized. Also, prevalence of IPEH may be underestimated as not all the cases are reported. Thus, considering that IPEH presents with many different clinical morphologies, in order to establish a more defined clinical profile and ease the diagnosis, it is advisable to report them in the literature.

According to Hashimoto, three types of IPEH are recognized [10]. Type I, primary or pure form, occurs within dilated vascular spaces, it is the most common subtype; type II is a secondary or mixed form that occurs in preexisting vascular lesions like hemangiomas, arteriovenous malformations or pyogenic granulomas; and type III or the undermined type is found in an extravascular location, the lesion develops in the bed of a hematoma and trauma is usually a prerequisite, it is the least common variant [10].

IPEH is a benign behavioral vascular lesion that must be accurately differentiated from malignant angiosarcoma and other vascular tumors $[1,11]$.

In the present case, histopathological analysis showed a well circumscribed intravascular lesion composed of papillary structures lined by a single layer of endothelial cells without atypia or necrosis; the latter finding supported the benign nature of the lesion. Intravascular thrombi were observed and no preexisting vascular lesion was demonstrated so it was classified as IPEH type I.

The IPEH does not tend to regress spontaneously, so the treatment of choice for this lesion is surgical excision with wide margins [12]. The prognosis of IPEH is excellent and recurrences are rare, like in our case.

\section{CONCLUSiOnS}

In summary, we present an exceptional case of IPEH located to the vermillion border with an atypical clinical presentation as it lacked a vascular appearance. The oral mucosa is commonly affected by vascular lesions so it is worthy to consider IPEH in the differential diagnosis.

\section{ACKNOWLEDGEMENTS}

All authors would like to thank dietitian Jesús Antonio Hernández Morales, for his technical assistance.

\section{REFERENCES}

1. Akdur, N. C., Donmez, M., Gozel, S., Ustun, H., \& Hucumenoglu, S. (2013). Intravascular papillary endothelial hyperplasia: histomorphological and immunohistochemical features. Diagnostic pathology, 8(1), 167.

2. Masson, M.P.(1923). Hemangioendotheliome végétant intra-vasculaire. Bull Soc Anat Paris, 93: 517-23.

3. Heyden, G., Dahl, I., \& Angervall, L. (1978). Intravascular papillary endothelial hyperplasia in the oral mucosa. Oral Surgery, Oral Medicine, Oral Pathology, 45(1), 83-87.

4. Henschen, F. (1932). L'endovasculite proliferante thrombopoietique dans la lesion vasculaire locale. Ann. Anat. Pathl.(Paris)., 9, 113.

5. Clearkin, K. P., \& Enzinger, F. M. (1976). Intravascular papillary endothelial hyperplasia. Archives of pathology \& laboratory medicine, $100(8), 441$.

6. Sarode, G. S., Sarode, S. C., \& Karmarkar, S. P. (2014). Oral intravascular papillary endothelial hyperplasia (Masson's tumor): a review of literature. Journal of Oral and Maxillofacial Surgery, Medicine, and Pathology, 26(1), 73-79.

7. Sarode, G. S., \& Sarode, S. C. (2015). Extra-vascular type of oral intravascular papillary endothelial hyperplasia (Masson's tumor) of lower lip: A case report and review of the literature. Indian Journal of Dental Research, 26(1), 101.

8. Tedla, M., Bežová, M., Biró, C., Tedlová, E., Eng, C. Y., \& Zeleník, K. (2014). Intravascular papillary endothelial hyperplasia of larynx: case report and literature review of all head and neck cases. Otolaryngologia Polska, 68(4), 200-203.

9. Guledgud, M. V., Patil, K., Saikrishna, D., Madhavan, A., \& Yelamali, T. (2014). Intravascular papillary endothelial hyperplasia: diagnostic sequence and literature review of an orofacial lesion. Case Reports in Dentistry, 2014.

10. Hashimoto, H., Daimaru, Y., \& Enjoji, M. (1983). Intravascular papillary endothelial hyperplasia. A clinicopathologic study of 91 cases. The American journal of dermatopathology, 5(6), 539-546.

11. Tutar, O., Samanci, C., Bakan, S., Alis, D., Kaur, A., Şanlı, D. T., \& Yildirim, D. (2015). Typical MDCT Angiography Findings of an Unusual Cutaneous Neoplasia; Masson Tumor. Polish Journal of Radiology, 80, 36.

12. Cohen, A., Maly, A., \& Azaz, B. (2009). Intravascular papillary endothelial hyperplasia of the lower lip: surgical approach and review of the literature. Gerodontology, 26(4), 305-308. 